\title{
METODOLOGÍA PARA LA CARACTERIZACIÓN Y DIFERENCIACIÓN DE LAS UNIDADES DE PAISAJE DE UN ESPACIO DE MONTAÑA: LAS SIERRAS DE BÉJAR Y CANDELARIO ${ }^{1}$
}

\author{
Rubén Fernández Álvarez \\ Departamento de Geografía. Universidad de Salamanca. \\ rfa@usal.es
}

\section{RESUMEN}

La creciente preocupación en materia de protección del paisaje por parte de la administración, a raíz de la elaboración del Convenio Europeo del Paisaje, ha fomentado una nueva forma de análisis del mismo encaminada a comprender sus elementos y su posible evolución con el paso del tiempo. La metodología seguida en este artículo se basa en la diferenciación de las unidades de paisaje y se ve complementada con la utilización de aspectos procedentes del Análisis Sistémico del Paisaje, identificando así los geosistemas que conforman el mismo en un espacio de montaña que se toma como estudio de caso.

Palabras clave: Convenio Europeo del Paisaje, Paisaje, Geosistema, Unidad de paisaje, Sierras de Béjar y Candelario, Áreas de montaña.

\footnotetext{
ABSTRACT

The growing concern for the protection of the landscape by the administration, following the development of the European Landscape Convention, has encouraged a new form of landscape analysis intended to understand the elements pertaining to it and its possible

Fecha de recepción: septiembre 2011.

Fecha de aceptación: septiembre 2012.

1 El presente artículo se inscribe en los resultados del proyecto de investigación «Dinámica socioeconómica y articulación espacial de las montañas interiores en España. Experiencias y orientaciones para el desarrollo territorial sostenible y la política de cohesión territorial» (Ministerio de Educación y Ciencia, referencia SEJ200767655-C05-01).
} 
evolution in time. The methodology used in this article is based on the differentiation of landscape units and is complemented by the use of aspects of systemic analysis of the landscape, thus identifying the geosystems that make up the mountain landscape in an area of study.

Key words: European Landscape Convention, Landscape, Geosystem, Landscape unit, Mountains of Béjar and Candelario, Mountain areas.

\section{INTRODUCCIÓN: EL PAISAJE Y SU TRATAMIENTO}

Una de las virtudes más significativas del territorio, especialmente en un espacio de montaña, es su paisaje, elemento éste que, «a ojos humanos», es capaz de caracterizar una zona por su belleza, por sus formas, es decir, «el paisaje es lo que permite definir la «personalidad» geográfica de los lugares» (Martínez de Pisón 2000a: 16); por lo tanto es necesario saber interpretarlo, cuáles son los elementos que lo componen, cómo se interrelacionan entre sí, cuál es su dinámica, para así estar en disposición de valorarlo por su calidad intrínseca y no sólo por su belleza, cualidad esta de notable subjetividad sujeta a la interpretación del individuo (Martínez de Pisón 2000a; Zoido Naranjo, 2000). El paisaje es el máximo exponente de la evolución natural y cultural de un territorio, así en él se pueden interpretar las tendencias seguidas por las actividades antrópicas, convirtiéndose en una notable fuente de información a este respecto. En determinadas ocasiones el paisaje se convierte en un elemento de identidad para sus propios habitantes, «ya que la organización social tradicional es creadora de paisaje» (Martínez de Pisón 2000b: 218); sirvan de ejemplo los ganaderos «pasiegos», que han esculpido uno de los paisajes antrópicos más valorados de la Península Ibérica, el paisaje del «Valle del Pas».

Las propuestas conservacionistas sobre el paisaje surgen durante el siglo XIX, activadas en cierto modo por las nuevas orientaciones del romanticismo (Ortega Cantero, 2000), pero no es hasta finales del siglo XX y principios del XXI cuando podemos observar una serie de actuaciones (de los entes públicos) dirigidas a protegerlo, erigiéndose como punto álgido el Convenio Europeo del Paisaje, pues hasta entonces, en lo que a la legislación española se refiere, el paisaje no ha sido tratado como un elemento a proteger en los diversos documentos normativos y de planificación (Zoido Naranjo, 2000), sólo en determinadas excepciones aparecen someras referencias a lugares de notable belleza.

Desde la aprobación en el año 2000 del Convenio Europeo del Paisaje (en adelante CEP) por el Comité de Ministros del Consejo de Europa, gracias a la preocupación existente por destacar al paisaje como un elemento significativo de la calidad de vida, como un recurso para el desarrollo y como patrimonio histórico-cultural (Sanz Herráiz, 2000; Mata Olmo, 2004; Silva Pérez, 2009), estamos en los albores de la creación de un marco normativo internacional que sienta las bases para la gestión, conservación y ordenación de los paisajes. Con una visión integradora y totalizadora, el CEP no hace distinción entre paisajes según su calidad, sino que, en su artículo segundo, hace referencia a la totalidad del territorio, independientemente del grado de conservación o degradación (Zoido Naranjo, 2000; Mata Olmo, 2004). Con la elaboración del CEP se está creando una definición objetiva del termino 
«paisaje», sin la cual no sería posible la aplicación de medidas jurídicas en el mismo (Zoido Naranjo, 2000) porque no es posible gestionar y ordenar elementos en los que la subjetividad está en la base de sus fundamentos, como ocurría con el término «paisaje» anteriormente.

La ratificación y posterior aprobación, por parte del Parlamento español, del CEP lleva emparejada la creación de centros específicos dedicados a dotar a los entes públicos de las herramientas adecuadas, para que la gestión y ordenación del paisaje siga las vías correctas, además de orientar sobre la aplicación del CEP. Los centros más significativos creados en España son el Centro de Estudios Paisaje y Territorio (dependiente de la Consejería de Obras Públicas y Vivienda de la Junta de Andalucía y de las Universidades públicas de Andalucía) y el Observatori del Paisatge (dependiente del Departament de Política Territorial i Obres Públiques de la Generalitat de Catalunya). En estos centros se han elaborado, desde su creación, numerosos catálogos paisajísticos, además de promover diversas metodologías de trabajo y análisis del paisaje.

Fuera del marco normativo, que se implanta a raíz de la elaboración del CEP, la tendencia investigadora en materia de paisaje ha evolucionado hacia la vertiente dinámica del mismo, es decir, en la actualidad los estudios paisajísticos se preocupan por analizar, describir y sintetizar las características dinámicas del mismo, convirtiéndose necesario para ello el conocimiento de los factores pretéritos y actuales de la configuración y organización del paisaje, con el objeto de prever su orientación futura, erigiéndose, así, en herramienta fundamental las nuevas tecnologías de la información, especialmente los Sistemas de Información Geográfica (SIG). La creciente calidad de los materiales disponibles (imágenes de satélite, ortofotografías aéreas, diversidad de programas informáticos de tratamiento de datos e imágenes, modelización 3D, etc.), junto con las nuevas metodologías de análisis de los paisajes, están desarrollando una muy nutrida bibliografía paisajística que facilita su más profundo y avanzado conocimiento y convierte en más precisa la predicción sobre la evolución del paisaje. De entre las nuevas formas de analizar y estudiar el paisaje, sobresale el modelo británico «Landscape Character Assessment» (LCA), creado por The Countryside Agency y Scottish Natural Heritage con el objetivo de obtener el carácter del paisaje, realizando para ello, además de los preceptivos estudios del medio físico, un exhaustivo estudio de los factores antrópicos actuales y pasados con el objeto de pronosticar la posible evolución del paisaje. Es de destacar, dentro del proceso de aplicación de este método, su flexibilidad en cuanto a la interpretación de los pasos a seguir en función de las tendencias paisajísticas locales.

Parece recomendable hacer un breve repaso, inicialmente, de algunas de las definiciones de «paisaje» y de «unidad de paisaje» que, tanto distintos organismos como investigadores en la materia, han ido proporcionando, transformando y completando a lo largo del tiempo, pues nos van a facilitar algunas de las pautas metodológicas para la diferenciación entre unidades.

Georges Bertrand (1968), uno de los referentes más sobresalientes en los estudios sobre el paisaje desde su centro de Toulouse-Le Mirail, investigador de cita imprescindible al hablar sobre el paisaje, coordinador de múltiples estudios, autor de diversas y numerosas publicaciones en este ámbito y director de diferentes trabajos de investigación sobre el particular, define el paisaje como: «...porción de espacio caracterizado por un tipo de combinación dinámica, y por consiguiente inestable, de elementos geográficos diferenciados -físicos, biológicos y antrópicos- que, al actuar dialécticamente unos sobre otros, hacen del paisaje 
un conjunto geográfico indisociable que evoluciona en bloque, tanto bajo el efecto de las interacciones entre los elementos que lo constituyen como bajo el efecto de la dinámica propia de cada uno de los elementos considerados separadamente».

En la Geografía española, tanto a partir de la profundización y continuidad de las aportaciones que en su momento ya hiciera el profesor Terán, como en estrecha interdependencia con las contribuciones y avances procedentes de la escuela francesa (profesor Bertrand y otros colegas y discípulos), son referencias imprescindibles en la ciencia y estudio del paisaje los equipos de trabajo de la Universidad Autónoma de Madrid (profesores Martínez de Pisón, Sanz Herráiz o Mata Olmo), de la Universidad de Barcelona (profesora Bolós i Capdevia) y, con algo de posterioridad, de la Universidad de Granada (Rodríguez Martínez, Jiménez Olivencia y Gómez Zotano). Martínez de Pisón (2009:36) entiende el paisaje como la configuración de la realidad geográfica completa o, si se prefiere, la morfología de los hechos geográficos», concepción muy en consonancia con la que Dollfus (1978:13) exponía cuando afirmaba que «el paisaje es el aspecto visible, directamente perceptible, del espacio....se describe y se explica partiendo de las formas, de su morfología». Es esa dimensión formal la que comparten las definiciones de Dollfus y Martínez de Pisón.

Por su parte, Sanz Herráiz subraya, al definir el paisaje, las dimensiones formal, territorial y, evolutiva e interactiva como ejes básicos para su concepción. Y así afirma que «el paisaje es un fenómeno que se manifiesta en la superficie de la tierra, es un hecho territorial, expresión última o actual de una larga historia de interacción entre las diferentes esferas que se encuentran en la faz de la Tierra» (Sanz Herráiz, 2000: 282). Este último aspecto, el de la interrelación entre distintos ámbitos, es el que ya el propio Bertrand destacaba en sus primeros estudios sobre el paisaje cuando hablaba de los tres subconjuntos (las «esferas»de las que habla Sanz Herráiz) en que el geógrafo debe descomponer el conjunto del paisaje global: potencial ecológico, explotación biológica y utilización antrópica.

No faltan, en fin, tampoco, autores que han contribuido a enriquecer la concepción y entendimiento del paisaje incidiendo en otras dimensiones, como la unión entre ecología y cultura, afirmando que «el paisaje es identificado como síntesis de los elementos ecológicos y culturales que lo constituyen» (López Barajas y Cervantes Borja, 2002: 44), o remarcando su orientación evolutiva y su consideración como producto resultante de procesos y factores de distinta naturaleza y procedencia, como señala Ribas Vilás al decir que «el paisaje ha presentado, durante el largo periodo de desarrollo de la Tierra, distintas formas y relaciones. En un principio el paisaje estaba constituido solamente por los elementos físicos o abióticos. La aparición de vida sobre la Tierra aportó nuevos elementos al paisaje, pasando éste a ser físico y biótico. Con el hombre, el paisaje se convirtió gradualmente en un sistema físicobiótico-antrópico» (Ribas Vilás, 1992: 135).

Por su parte, la definición de paisaje que el CEP hace en su artículo $1^{\circ}$ apartado «a» es la siguiente: «por paisaje se entenderá cualquier parte del territorio tal como la percibe la población, cuyo carácter sea el resultado de la acción y la interacción de factores naturales y/o humanos».

Los diferentes autores coinciden en la definición del término paisaje, destacando todos ellos la interrelación existente entre el hombre y el medio natural como eje vertebrador de éste. Fácilmente interpretable el carácter evolutivo del paisaje en la definición de Bertrand, quizás el resto de definiciones no lo matizan, es decir, no reflejan en la definición de paisaje 
una característica básica del mismo, característica de notable importancia que condiciona la percepción del paisaje con el paso del tiempo. Sí es verdad que todas las definiciones, implícitamente, reflejan el dinamismo evolutivo del paisaje, pues siempre que existan interrelaciones hombre/medio, medio/medio u hombre/hombre el paisaje se va a ver afectado y, por tanto, se va a producir un cambio en él. Además de la característica ya mencionada (dinamismo evolutivo) el paisaje posee la cualidad inherente de la escala, del tamaño: desde el micropaisaje de decímetros cuadrados, a la Tierra como paisaje universal; dependiendo del estudio, del observador, el término paisaje puede adquirir diversas acepciones.

Resulta necesario a la hora de definir el termino «paisaje» tener en cuenta ciertas apreciaciones, que son inherentes a las características del paisaje y que no pueden caer en el olvido. Hay que destacar en su definición su tendencia evolutiva, es decir, el paisaje es dinámico y por tanto está sujeto a la modificación de los elementos que lo integran. En segundo lugar no se debe asociar el paisaje con la percepción subjetiva de la belleza, pues es aquí cuando la interpretación de su evaluador juega un papel destacado. Un paisaje natural que, a priori, puede ser muy bello no tiene por qué ser más diverso que un paisaje antrópico, hay que discernir entre estética y riqueza paisajística y valorar también el paisaje por su diversidad. En último lugar un aspecto fundamental que debe ser destacado, es la relación existente entre el hombre y el medio, pues en la actualidad el ser humano ha sido capaz de modificar el medio natural siendo muy pocos los lugares donde la acción antrópica no haya influido de forma determinante, por tanto es conveniente incluir en su definición esta acción. Así, se puede definir el paisaje como «el conjunto dinámico natural, humano o mixto en el que convergen las interrelaciones entre los factores naturales y antrópicos y tiene repercusión visual independientemente de su mayor o menor diversidad y de su calidad».

Respecto a lo que pueda entenderse como «unidad de paisaje» son varias, asimismo, las definiciones que ayudan a ello. Todas ellas, a diferentes niveles, destacan como característica de notable relevancia el factor homogeneidad para diferenciar una unidades de otras. Además de este factor, homogeneidad, se debe enfatizar la propia interrelación entre los elementos que las constituyen. Así, por ejemplo Ibarra Benlloch (1993: 231) subraya la fisonomía como nota fundamental en su concepción, pero también destaca la escala, afirmando que «entendemos las unidades de paisaje como espacios que, a una escala determinada, se caracterizan por su fisionomía homogénea y una evolución común, siendo de unas dimensiones concretas y cartografiables». Más compleja, integradora y plural es la forma que tienen otros autores de concebir las «unidades de paisaje», al afirmar que «constituyen estructuras de componentes físicos, bióticos y antrópicos, funcionalmente integradas, derivando a unidades geoecológicas ligadas vertical y horizontalmente, en tiempo y espacio» (López Barajas y Cervantes Borja, 2002: 44). Precisamente esta doble dimensión -espacio y tiempo-, constituye una referencia fundamental para Bertrand al intentar precisar el alcance y el entendimiento de las «unidades de paisaje», además de subrayar nuevamente la versatilidad de la escala de las mismas: «todas las delimitaciones geográficas son arbitrarias y es imposible encontrar un sistema general del espacio que respete los límites propios de cada orden de fenómenos. Sin embargo, se puede contemplar una taxonomía de los paisajes geográficos con dominante física a condición de fijar de antemano los límites» (Bertrand, 2006: 44).

Desde una perspectiva más concreta y, sobre todo, práctica y aplicada, Sabaté Bel y vera Galván aportan una definición que convierte en más operativas a estas piezas en la 
configuración del paisaje y en la que se subraya su singularidad y su carácter multiescalar: «combinaciones singulares, aunque agrupables en familias y asociaciones, de componentes temáticas, espaciales y temporales. Tales combinaciones son entendidas como combinaciones autónomas (el todo es más que la suma de las partes). Las Unidades de Paisaje pueden y deben ser definidas en múltiples niveles, de modo que unidades de un nivel podrían anidar o contener parcialmente unidades de otros niveles». (Sabaté Bel y Vera Galván, 2008: 63-64). En parte, también esa singularidad a la que aludía esta última definición es la que igualmente le sirve a Nogué para su contribución conceptual, y también se apoya en la «homogeneidad» que destacaban definiciones anteriores, como la de Ibarra Benlloch, y así afirma que «las unidades del paisaje son porciones del territorio con un mismo carácter, es decir, están caracterizadas por un conjunto de elementos que contribuyen a que un paisaje sea diferente de otro, y no por ello mejor o peor.» (Nogué i Font, 2007: 52).

En último término, desde ámbitos normativos y de gestión, también se ha querido hacer especial hincapié en la funcionalidad, sentido y trascendencia que alcanzan las «unidades de paisaje», proporcionando un concepto de las mismas que actúe como contexto o marco de adecuación para la planificación y ordenación del paisaje y en el cual se detectan parte de las especificidades que las definiciones anteriores han señalado. Así sucede con los contenidos que a este respecto recoge el Reglamento de Paisaje de la Comunidad Valenciana (Decreto 120/2006, artículo 32.2), donde se entiende por «unidad de paisaje» «el área geográfica con una configuración estructural, funcional o perceptivamente diferenciada, única y singular, que ha ido adquiriendo los caracteres que la definen tras un largo período de tiempo. Se identifica por su coherencia interna y sus diferencias con respecto a las unidades contiguas». En estas últimas características de la definición reside la especificidad de estas unidades.

La propuesta que en este documento se presenta, está orientada a destacar todos esos valores intrínsecos que posee el paisaje desde la caracterización y definición de una tipología de unidades de paisaje de un espacio de montaña y la organización de las mismas dentro de los geosistemas que lo componen.

\section{METOdOLOGÍA}

El desarrollo de este trabajo se ha articulado, partiendo de los fundamentos teóricos anteriores sobre la definición de paisaje, en el desarrollo de tres etapas, siendo la primera de ellas la identificación de los factores naturales y antrópicos que afectan al espacio serrano seleccionado como estudio de caso. La segunda de las etapas está centrada en la definición y caracterización de las diferentes unidades del paisaje y en la identificación de los criterios utilizados para ello. Una vez definidas las unidades del paisaje, la tercera de las etapas es la consistente en aplicar las unidades diferenciadas en un método de análisis paisajístico, en este caso se han empleado las unidades de paisaje, mediante su interrelación, para identificar los geosistemas (siguiendo la terminología de Bertrand) de las sierras de Béjar, y Candelario, según el proceso metodológico dictado por el Análisis Sistémico del Paisaje.

La definición de paisaje, anteriormente expuesta, que proporciona el Convenio Europeo nos sirve como punto de partida para la subdivisión de las unidades del paisaje, creándose así dos bloques: las unidades naturales y las unidades antrópicas. No sólo la interpretación de su definición sirve como motivación en esta primera subdivisión, sino que son los criterios de 
Figura 1

ESQUEMA ALTITUDINAL «TIPO» DE POSIBLE LOCALIZACIÓN DE LAS DIFERENTES UNIDADES DE PAISAJE

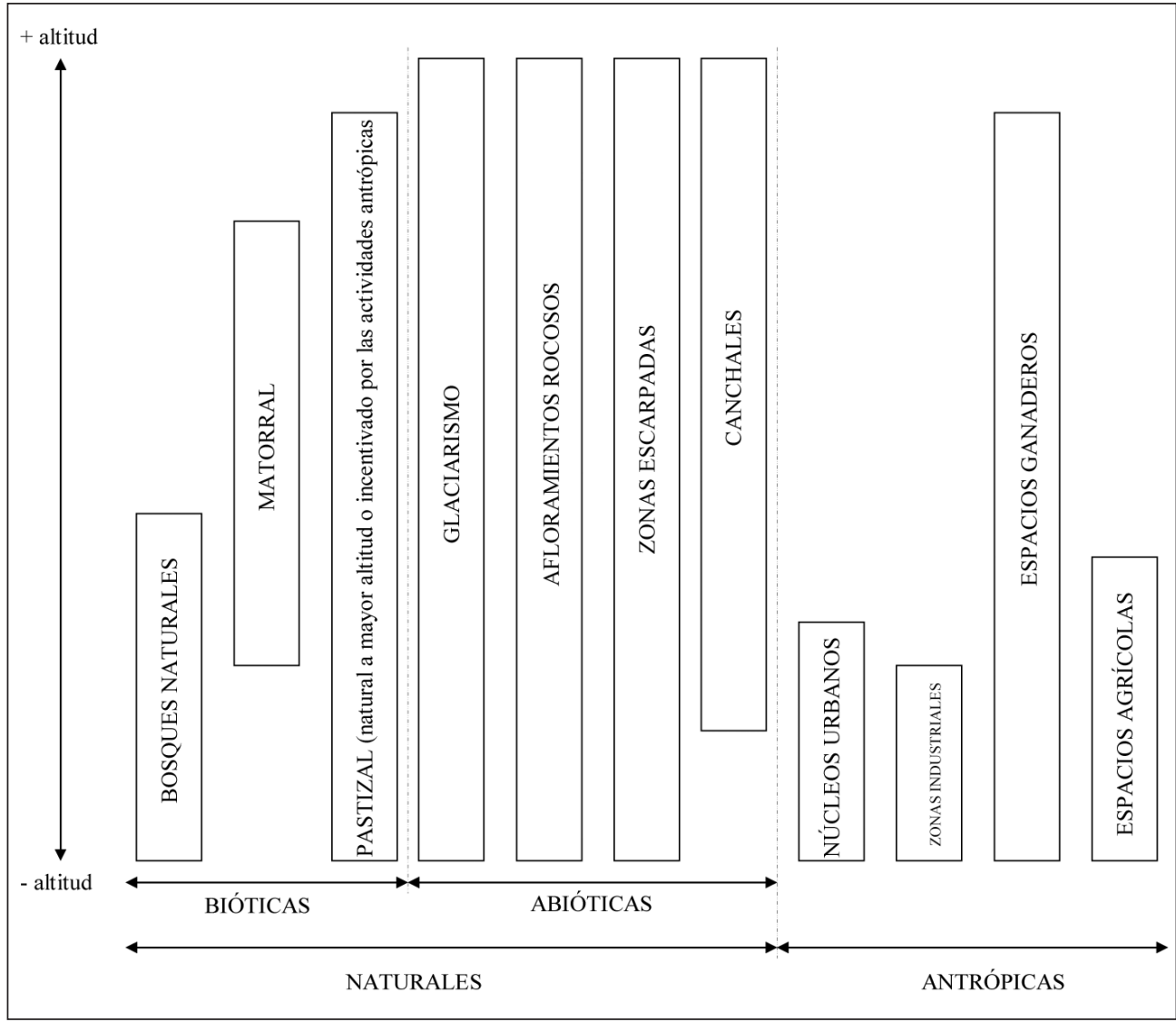

Fuente: elaboración propia.

homogeneidad (Sanz Herráiz, 2000) los que adquieren mayor relevancia, lo natural frente a lo antrópico. Gran parte de nuestro trabajo se apoya en el citado criterio de homogeneidad, pero matizado, dependiendo de las unidades a las que se refiera; por ejemplo, en el caso de las unidades de paisaje naturales bióticas, además de las similitudes existentes entre los elementos ha de destacarse todo lo relativo a la fisonomía. No solo se tendrán en cuenta las razones de uniformidad, sino que también se atenderán las propuestas de otros autores y sus principios a la hora de determinar las diferentes unidades que componen el paisaje. La combinación de la forma del relieve y los usos del suelo caracterizarán cada una de las unidades que se definan a continuación, a las que se añadirán los valores socio-culturales más significativos para crear, así, una serie de unidades del paisaje en las que no sólo se incluyan los valores físicos y ambientales, sino también los sociales y culturales. 
Figura 2

UNIDADES DE PAISAJE PRINCIPALES DE UN ESPACIO DE MONTAÑA

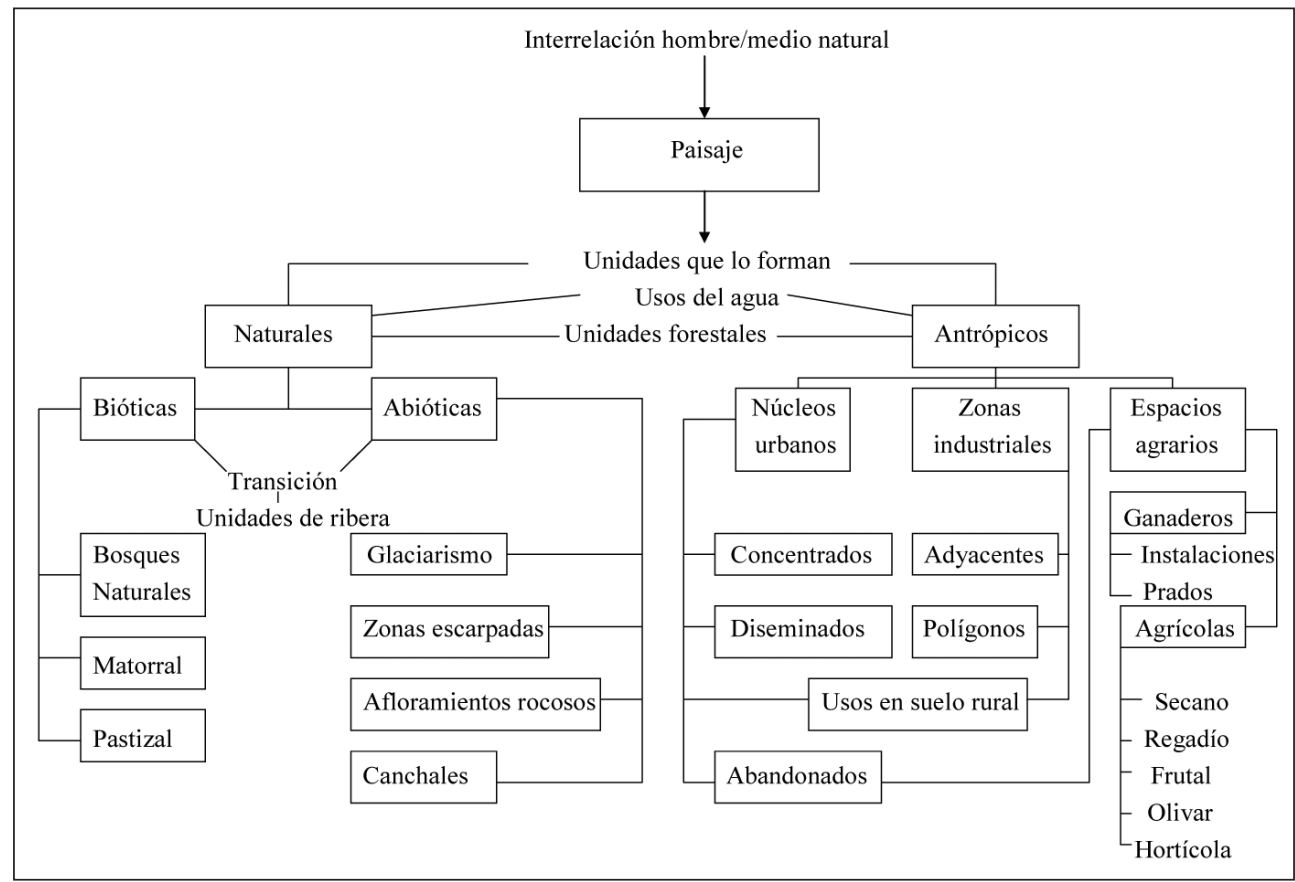

Fuente: elaboración propia.

Antes de comenzar a sintetizar los aspectos metodológicos utilizados para llevar a cabo la subdivisión del paisaje de una zona de montaña en unidades de paisaje o elementos que integran el paisaje, es necesario hacer una primera subdivisión zonal dentro de un espacio de montaña idealizado ${ }^{2}$ a tal fin. Tres son los lugares zonales, a grandes rasgos, que podemos distinguir dentro de una montaña: zona de cumbres, zona de vertiente o ladera, zona de piedemonte o fondo de valle, lugares estos donde se lleva a cabo la distribución y localización de las diferentes unidades de paisaje, además de otorgarles a cada una de ellas unos rasgos significativos por el hecho de encontrarse situadas en un lugar u otro, rasgos tales como mayor o menor pendiente, condiciones climáticas, limitaciones altitudinales, etc. (fig. 1).

Apoyándonos en las diferentes definiciones de paisaje analizadas, en las que se destaca la interrelación hombre/medio natural como fuente del mismo, la forma más adecuada de enfrentarnos al inventario sigue la línea de la diferenciación entre lo natural y lo antrópico, creando así el punto de partida de nuestro inventario de unidades de paisaje (fig. 2). Esta primera diferenciación va a marcar la evolución en la caracterización de la tipología de unidades paisajísticas.

2 Se trata de una modelización tipo de una zona de montaña, donde los factores altitud, pendiente y clima inciden notablemente sobre las unidades de paisaje que se localizan. En función de estos factores la distribución de las mismas puede sufrir variaciones y verse distorsionada, al igual que la acción antrópica, que puede ser de mayor o menor incidencia. 
Figura 3

CRITERIOS DE DIFERENCIACIÓN DE LAS PRINCIPALES UNIDADES DEL PAISAJE

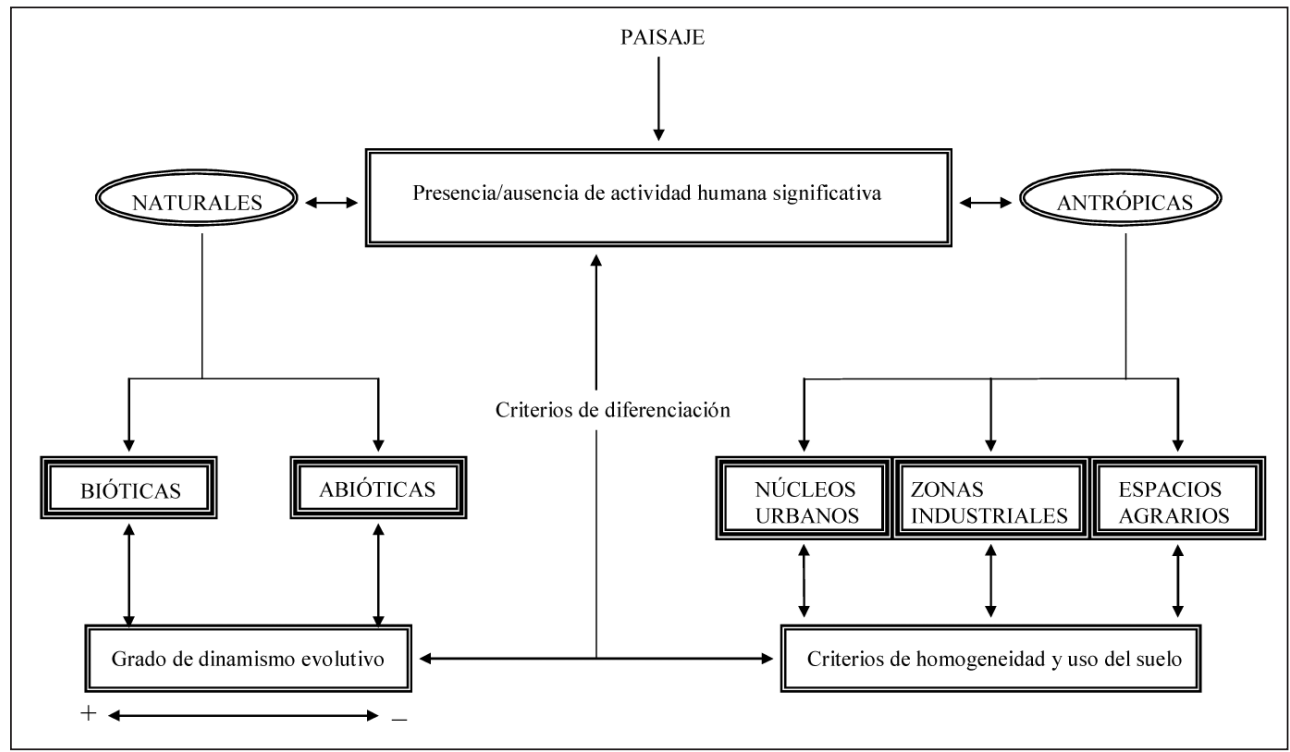

Fuente: elaboración propia.

Dentro de las unidades de paisaje naturales surge la necesidad de distinguir entre lo biótico y lo abiótico, diferenciando, de este modo, entre unidades con notable grado de dinamismo evolutivo (biótico) y unidades con grado de evolución sostenido en el tiempo (abiótico). En el caso de las unidades antrópicas seguimos la tendencia evolutiva marcada por las definiciones de «unidad de paisaje», diferenciando así tres tipos de unidades primarias: núcleos urbanos, zonas industriales y zonas de aprovechamiento agrario.

\section{Unidades de paisaje naturales}

Están compuestas por tres tipos de unidades primarias, las unidades bióticas, las abióticas y las unidades de transición entre las dos anteriores. Esta categoría queda subdividida en tres tipos de unidades, tomando como referencia el grado de dinamismo evolutivo (fig. 3), así el periodo de tiempo se convierte en un factor notable en esta unidad, pues no evolucionan en los mismos rangos temporales. En el caso de las unidades bióticas, formadas por seres vivos, no necesitan grandes periodos de tiempo para transformarse, basta con unas decenas de años para que un campo de cultivo o un prado abandonado se regenere y alcance un porte arbustivo o subarbóreo. Por su parte, las unidades abióticas están formadas por elementos inertes y su dinamismo evolutivo depende de factores externos como los procesos erosivos. En esta diferencia entre unidades surge la causa principal de establecer una primera división dentro de las unidades de paisaje naturales. Hay, además, un tercer grupo o categoría que sirve de transición entre las unidades bióticas y abióticas: la unidad de paisaje de ribera (fig. 2). Esta 
unidad está formada tanto por elementos bióticos (vegetación de ribera) como por elementos abióticos (río y cauce), por lo que resulta complicado situarla dentro de un tipo de unidad o de otro, ejerciendo así como unidad transitoria entre ambos; además se incluye una unidad propia de transición, pues el cambio entre unidades de paisaje no siempre se da de forma nítida, sino que sigue una gradación desde una unidad a la adyacente.

\subsection{Unidades de paisaje bióticas}

Este tipo de unidades están formadas en exclusiva por elementos que tienen vida (vegetación) y que además surgen en el medio de forma natural, sin intervención humana ${ }^{3}$. Las unidades de paisaje bióticas se componen de una serie de subunidades que les dan forma y caracterizan. Los criterios de diferenciación para estas unidades están en relación con aspectos fisionómicos de la vegetación y con las características orográficas de los lugares donde se sitúan; así, según el estrato de las formaciones vegetales, pueden encontrarse tres tipos de subunidades de paisaje, como son: bosques naturales, matorral y pastizal; además debemos incluir las zonas de transición entre una y otra unidad. «Las unidades de paisaje vegetal cuya valoración se plantea son definidas, pues, teniendo en cuenta no solamente el ecosistema subyacente, sino como conjunto plástico de elevado contenido estético. Así diferenciada, la unidad aparece relativamente homogéne a desde el punto de vista perceptivo, por representar cambios fisionómicos en el territorio» (De Lucio et al., 1990). "Cada unidad fisionómica definida responde a una unidad ecológica, quedando resuelto el problema de la obtención de unidades de paisaje en relación a unidades ambientales a una escala o grado de detalle con coherencia visual» (Meaza y Ormaetxea, 1992: 374). Este criterio de diferenciación basado en la fisonomía vegetal ha de apoyarse además en el clima que afecta a la zona de estudio, en la pendiente y en los factores edáficos, pues son factores, los tres, que la condicionan. Las subunidades ya citadas en este apartado se complementarán con otras dos subunidades, como son la de pastizal con roquedo y la de matorral con roquedo, siendo, así, el roquedo el que introduce una nueva forma de interpretación de estas unidades, pasando así de haber un elemento principal en la unidad (como era el estrato vegetal) a haber dos elementos principales (el estrato vegetal y el roquedo ${ }^{4}$ ). La característica principal de estas unidades de paisaje está marcada por el porte de la vegetación que las integra y por su situación dentro del contexto orográfico pudiendo ser diferenciadas, no sólo por la cubierta del suelo, sino también por la pendiente dominante en su localización, pues no se percibe igual un bosque de determinada especie, independientemente de su porte, en un fondo de valle que uno localizado en la vertiente de la montaña.

3 A pesar de tratarse de elementos naturales, siempre se debe tener en cuenta que las acciones antrópicas han podido incidir en ellas, no implantándolas, pero sí condicionándolas para favorecer su desarrollo. Sirvan de ejemplo los «bosques ahuecados» con fines agrarios, una vez abandonados son ocupados incipientemente por el matorral iniciándose así un periodo evolutivo encaminado a alcanzar el estadio climácico, siendo entonces cuando el bosque ocuparía su espacio originario.

4 Es habitual encontrar en los espacios de montaña «canchales» o «berrocales» dependiendo de los agentes geomorfológicos actuantes y de los materiales que forman el sustrato, apareciendo así las citadas unidades de paisaje. 


\subsection{Unidades de paisaje abióticas}

Las forman elementos inertes y naturales. Las unidades de paisaje abióticas se diferencian siguiendo criterios erosivos, morfológicos y de homogeneidad, obteniendo así tres subunidades: zonas escarpadas, afloramientos rocosos y canchales. Además de las tres subunidades citadas debemos incluir una más que está formada a la vez por estas tres subunidades, las zonas caracterizadas por las huellas del glaciarismo y periglaciarismo. Se definen las zonas caracterizadas por las huellas del glaciarismo como unidad de paisaje porque posee unas características morfológicas que lo hacen fácilmente identificable en el territorio. Tenemos que tener en cuenta que se trata de una unidad especial, pues dentro de ella podemos encontrar algunas de las unidades de paisaje que ya hemos citado con anterioridad. Esta unidad glaciar, a su vez, es subdividida en tres pequeñas unidades diferenciando así los diferentes procesos genéticos de estas zonas: unidad de circo, unidad de valle y unidad de morrena. Con esta subdivisión se acentúan las características morfológicas que el glaciarismo incluye en el paisaje. Estas unidades están caracterizadas principalmente por la presencia de los elementos geológicos y geomorfológicos y donde las diferentes acciones erosivas no permiten la presencia, en la actualidad, de elementos bióticos tales como la vegetación.

\subsection{Unidades paisajísticas de transición entre las bióticas y las abióticas}

Son unidades peculiares, pues el factor definitorio que las caracteriza es la presencia de varias unidades naturales que se mezclan en el territorio creándose así una zona de notable diversidad paisajística. Se trata de una unidad difícilmente cartografiable por su reducido tamaño (en nuestra escala de trabajo) y en la que los límites presentan gradación en el territorio, pues se pasa progresivamente de esta unidad, a las subunidades que la forman.

Dentro de las unidades de transición surge una nueva unidad, como es la unidad de ribera. Esta unidad queda situada como unidad de transición, porque son dos los elementos que la forman, por un lado una corriente de agua y su cauce (abiótico) y por otro la vegetación propia de ribera (biótico).

\section{Unidades paisajísticas de origen antrópico que están formadas por elementos naturales}

En los sistemas montañosos es habitual encontrarse con dos unidades paisajísticas de origen antrópico que están formadas por elementos naturales. Siguiendo el primer criterio que aplicamos (sujeto a la definición de paisaje) y el factor homogeneidad, delimitamos dos nuevas unidades de paisaje como son los paisajes asociados a los usos del agua y los paisajes forestales de repoblación. Estos paisajes de origen antrópico, pero con elementos naturales en su formación, modifican en gran medida la dinámica paisajística serrana y condicionan la evolución natural del paisaje, además de ocupar extensas áreas de territorio. Las unidades forestales de repoblación introducen un elemento nuevo dentro del paisaje serrano, apareciendo una serie de alineaciones de individuos arbóreos que denotan carácter de ordenamiento, al igual que sucede con la unidades bióticas, anteriormente citadas, éstas pueden ser subdivididas en función a los factores orográficos, especialmente la pendiente, pues serán interpretadas de una forma u otra según su localización en el contexto de la ladera. En cuanto 
a las unidades resultantes de los usos del agua (embalses y canales) introducen una nueva forma de paisaje, en la que cambian las pendientes, los usos y aprovechamientos, las formas vegetativas y animales y los ocupamientos humanos, rompiendo con la dinámica natural de la ladera serrana. Esta actividad antrópica se incluye como unidad de paisaje, a pesar de tratarse de un uso del suelo, por su notable repercusión.

\section{Unidades de paisaje antrópicas}

Unidades de paisaje delimitadas por criterios de diferenciación basados en la homogeneidad de las unidades. Cada unidad tiene como resultado un uso del suelo diferente (antrópico), creándose así una tipología característica definida por unidades urbanas, unidades industriales y espacios agrarios. La forma más adecuada para la caracterización de estas unidades antrópicas es la basada en los criterios morfológicos que presentan en el territorio y por la combinación de estructuras constructivas que en ella se desarrollan.

\subsection{Unidades paisajísticas de los sistemas de poblamiento}

Los sistemas de poblamiento introducen nuevas formas en el paisaje, formas que pueden ser las tradicionales (núcleos urbanos compactos y consolidados en nuestro caso) y nuevas formas que no siguen la tendencia tradicional. En orden a criterios de homogeneidad y compactación se han creado cuatro tipos de unidades: unidades de sistemas de poblamiento concentrados (núcleos de población), unidades de poblamiento diseminadas por el territorio, unidades de poblamiento ocupando el suelo rural y unidades de poblamiento abandonadas. La característica principal que determina la diferenciación de estas unidades está marcada por los elementos constructivos de las mismas, pues perceptivamente son claramente diferenciables los núcleos de nueva construcción que los que siguen una tendencia constructiva artesanal y de materiales autóctonos.

a) Unidades de poblamiento concentradas

La unidad referente a los sistemas de poblamiento concentrados, núcleos de población, tiene la finalidad de identificar sobre el espacio serrano los núcleos de población, su adaptación y cómo se integran en la dinámica general del paisaje de un espacio de montaña, introduciendo sobre el paisaje natural una nueva forma de paisaje antrópico.

b) Unidades de poblamiento diseminadas por el territorio

Principalmente el criterio de compacidad es el que va a definir esta unidad de paisaje; se trata de una unidad en alza en la última década del siglo XX y primera del siglo XXI, creándose así pequeñas «urbanizaciones» en las proximidades de los núcleos urbanos de residencias secundarias que sustituyen los usos agrícolas y ganaderos por usos de ocio y residenciales. Nos encontramos con una unidad que se extiende por el territorio creándose pequeñas parcelas con la presencia de una edificación. 
c) Unidades de poblamiento situadas sobre el espacio rural

Al igual que en la unidad anterior, va a ser la estructura constructiva, es decir, mayor o menor índice de concentración entre unas y otras construcciones en el espacio, el factor definitorio de esta unidad del paisaje. No existe esa compacidad, aparecen nuevos elementos dispersos por el territorio. Son espacios aislados que articulan el paisaje formando pequeñas parcelas ortogonales, introduciendo en el mismo las formas rectilíneas. Ocupan los espacios anteriormente dedicados a la ganadería, especialmente prados que se encuentran a poca distancia de los núcleos urbanos.

d) Unidades de los sistemas de poblamiento abandonados

Dos son los valores que definen esta unidad, la concentración y la homogeneidad de los elementos que la constituyen. Son núcleos compactos, en estado de abandono ocupados por la vegetación. Esta unidad nos puede dar una visión de la actividad regeneradora del medio natural, especialmente de la vegetación, nos aproxima hacia la posible tendencia de la dinámica evolutiva del paisaje serrano. Desde los comienzos del «éxodo rural» los núcleos rurales abandonados se han convertido en un elemento dominante en el paisaje que aparece de forma creciente en las montañas españolas. Además de por los elementos arquitectónicos, esta nueva unidad ha de caracterizarse por el proceso de colonización vegetal, pues el abandono favorece que las especies vegetales ocupen el territorio del que fueron desplazadas.

\subsection{Unidades de paisaje creadas por la ocupación industrial}

Los criterios de homogeneidad arquitectónica y de localización van a caracterizar a las siguientes subunidades industriales que pueden aparecen en los espacios serranos. No son unidades muy abundantes, pero sí muy características por su localización, pudiendo proporcionar una visión temporal, y muy valiosa, de la evolución de las normativas urbanísticas en esta materia (la industria) en los espacios de montaña. Las unidades de paisaje industriales no son muy habituales en la gran mayoría de los espacios montañosos de la Península Ibérica, pero sí son lo suficientemente representativas en aquellos espacios serranos localizados en el radio de acción de las ciudades industriales o de las ciudades con tradición industrial que en la actualidad se encuentran en desuso.

Tres son las unidades de paisaje que vamos a obtener definidas a través de los razonamientos ya citados al comienzo del párrafo y por los que se rigen las unidades antrópicas: homogeneidad arquitectónica y localización.

a) Unidades industriales adyacentes a los núcleos urbanos

Esta unidad va a introducir una nueva variable en el paisaje urbano, apareciendo una serie de infraestructuras destinadas a labores industriales; además esta unidad nos destacará la planificación, o no de la zona sobre la que se localizan. 
b) Unidades referidas a los polígonos industriales

No sólo los factores de homogeneidad y de localización van a marcar el carácter de esta unidad, sino que aparece un nuevo criterio, la distribución homogénea sobre un determinado lugar o parcela. La presencia o ausencia de esta unidad nos puede ofrecer una visión más o menos acertada sobre el grado de desarrollo industrial de una determinada zona. Con esta unidad se van a introducir variables poligonales sobre el paisaje (se crean a la percepción una serie de elementos ortogonales).

c) Unidades industriales sobre el espacio rural

Va a ser la localización la que determine esta unidad, surgiendo de forma aislada en un lugar a priori no destinado para esa labor. La presencia de esta unidad facilita una visión de la buena o mala planificación municipal en materia de urbanismo. Se trata de una unidad de paisaje que surge de forma aislada sobre un espacio destinado a usos rurales.

\subsection{Unidades paisajísticas de los espacios agrarios}

En la actualidad, debido a los ciclos económicos, los paisajes agrarios tienen un notable dinamismo evolucional, pues se producen continuos cambios en los usos y aprovechamientos del espacio agrícola y ganadero. Se sustituyen cultivos, la cabaña ganadera pasa de tener carácter extensivo a ser intensiva o semi-intensiva surgiendo así mayor número de establos y además aparece un factor determinante para la evolución paisajística como es el abandono agrario. Los criterios de delimitación y definición de las subunidades que forman esta unidad paisajística se centran en los usos del suelo, tal y como algunos autores han expresado «De entrada, debemos establecer los criterios de delimitación de las unidades paisajísticas y, tratándose de paisajes agrarios, parece que el criterio rector debe ser el de ocupación del suelo, pues un paisaje agrario no es más que la manifestación visual y perceptiva de los elementos que integran el espacio agrario en un territorio, con sus núcleos de poblamiento, con sus caminos o vías de comunicación, con sus espacios productivos agrícolas, con sus espacios ganaderos dedicados al cultivo de la hierba o al pasto a diente, con sus bosques organizados para la extracción de madera, leña, caza y productos silvestres, o con otros elementos artificiales o naturales, intervenidos o no, controlados o no, por la acción humana sobre el medio» (Molinero Hernando et al., 2009: 1214). Guiándonos por este método de delimitación de unidades agrarias según la ocupación del suelo, las subunidades resultantes son las siguientes: unidades paisajísticas ganaderas, unidades paisajísticas agrícolas y unidades agrarias abandonadas.

a) Unidades paisajísticas ganaderas

La ganadería en los espacios de montaña conduce a una ocupación del suelo que se estructura en dos vertientes, la vertiente de los aprovechamientos extensivos y la vertiente de los aprovechamientos intensivos, creándose así la unidad de los paisajes de los cercados (prados, extensivos) y la unidad de los paisajes de infraestructuras ganaderas (establos, 
infraestructuras para el movimiento del ganado, etc., unidades intensivas.). Los usos ganaderos crean unas unidades muy características ${ }^{5}$ dentro de las sierras que se distribuyen por la Península Ibérica, articulando el paisaje y dando una percepción de ordenamiento; el sistema de cercado.

Con esta unidad aparecen elementos poligonales que dotan al paisaje de un nuevo valor, el valor de las actividades tradicionales sobre el territorio (en nuestro caso los movimientos de ganado para el aprovechamiento de los pastos serranos). Esta red de cercados lleva implícita una red de caminos o sendas por las que mover al ganado, lo que supone un nuevo elemento lineal que vertebra y articula el paisaje, incidiendo sobre el mismo e introduciendo nuevas formas en las laderas montaraces.

En lo que a las infraestructuras ganaderas se refiere, se trata de una unidad de notable impacto visual, en aumento, sustituyéndose los materiales constructivos tradicionales y adaptados al medio, por nuevos sistemas que rompen con la armonía paisajística. Son destacadas como unidad de paisaje por suponer una nueva forma en el territorio, rompiendo la dinámica paisajística tradicional al introducir nuevas formas y nuevos elementos que distan notablemente de los elementos constructivos ganaderos tradicionales.

Estas unidades están caracterizadas por la interrelación de dos elementos, tres si poseen un sistema de cercado. La presencia de un espacio de pastizal, una cañada o vereda y un sistema de cercado son los elementos más significativos que normalmente diferencian estas unidades, aunque no son los únicos pues en estos lugares ganaderos puede existir la presencia de una cabaña o refugio que incluye así un nuevo carácter definitorio.

b) Unidades paisajísticas agrícolas

Siguiendo los criterios de delimitación ya establecidos (ocupación del suelo), las subunidades paisajísticas son las siguientes: usos agrícolas de secano, usos agrícolas de regadío, frutal, olivar y usos hortícolas. Tanto los usos agrícolas de regadío como los de secano, normalmente, son muy escasos en los espacios de montaña debido a los rigores climáticos y orográficos, pero es necesario identificarlas como unidades paisajísticas porque son un claro ejemplo de adaptación a las pendientes serranas. Los usos hortícolas se incluyen como unidad de paisaje porque se trata de un elemento característico de la economía de subsistencia, notable en los espacios serranos peninsulares y que ocupa gran parte de la superficie adyacente a los núcleos de población. Este tipo de economía se convierte en fundamental en época invernal, cuando las inclemencias meteorológicas hacen difícil la comunicación por carretera.

Las unidades referentes a frutales y a olivar introducen una nueva dinámica al paisaje serrano. Son unidades que no aparecen en todos los sistemas montañosos pero que adquieren notable importancia en los espacios serranos de la mitad sur peninsular. Estos dos usos convierten la ladera serrana en una maraña de bancales, imprimiéndole así una seña de identidad propia: las «montañas aterrazadas».

5 Los usos ganaderos o sistemas de organización ganadera van a depender en gran medida de la localización, pues los sistemas organizativos ganaderos de la «España atlántica» son notablemente contrastados respecto a los que surgen en la «España mediterránea», aunque en este apartado lo que se intenta resaltar es el carácter ortogonal que se obtiene de los sistemas de cercado, independientemente de los materiales que los originen. 
Éstas se caracterizan por el uso agrícola del suelo, pues son éstos los que las diferencian.

c) Unidades de los paisajes agrarios abandonados

En las últimas décadas este tipo de unidades se han convertido progresivamente en unidades que desempeñan un papel determinante en la regeneración paisajística natural de las montañas españolas. La catalogación de esta unidad de abandono y su posterior reflejo en la cartografía, incita a intuir la posible dinámica evolutiva de este paisaje serrano en el que progresivamente se sustituyen usos por abandono, encargándose así la regeneración natural de convertir lo antrópico en natural.

\section{Elaboración y definición de los Geosistemas de un espacio de montaña}

De forma muy somera se puede definir el termino «geosistema» como un sistema o modelo formado por una serie de elementos que interactúan entre sí (Bolós i Capdevila, 1992). Utilizado por primera vez en 1963 por el geógrafo Sochava, constituye una aplicación de la Teoría General de Sistemas (Gómez Zotano, 2006). «El geosistema es un concepto territorial, una unidad espacial bien delimitada y analizada a una escala dada» (Bertrand, 2006: 100) que se encuentra formada por una serie de variables que «se corresponden con los fenómenos de distribución espacial a la vez en plano vertical y en el horizontal» (Bertrand, 2006: 101). Dentro del nivel jerárquico expuesto por Bertrand (1978) para el Análisis Sistémico del Paisaje «el geosistema no se corresponde con la unidad elemental del paisaje, sino que en su interior pueden ser discriminadas varias unidades menores, correlacionables con facies de paisaje homogéneas, las geofacies» (Gómez Zotano, 2006: 32).

Ya obtenidas las diferentes unidades de paisaje y caracterizados aquellos elementos y usos del suelo que los forman, se está en disposición de elaborar una tipología de los «geosistemas» potenciales que integran el paisaje de montaña objeto de estudio o análisis, pues «existe una relación entre el geosistema y las unidades del paisaje que identifican a éste por su fisonomía: cada geosistema presenta una impresión característica a determinada escala que puede corresponderse con una imagen más o menos homogénea o, por el contrario constituir un verdadero mosaico de formas, color y textura» (Gómez Zotano, 2006: 32). Una de las principales características de los geosistemas es la relación existente, mediante combinaciones recíprocas, entre los tres factores que los integran: el potencial ecológico, la explotación biológica y la acción antrópica. La conjugación de los tres elementos mediante sus propias acciones de interacción facilita la caracterización de los geosistemas (Bertrand, 1968; Jiménez Olivencia y Porcel Rodríguez, 2008). «En el proceso de identificación y delimitación de los geosistemas, considerados éstos como unidades de paisaje de referencia, se diferencian siempre dos etapas. Una primera durante la cual se aborda el análisis separado de los distintos componentes del paisaje y otra posterior, que se centra en el establecimiento de las combinatorias de elementos» (Jiménez Olivencia y Porcel Rodríguez, 2008: 158). Por lo tanto la diferenciación de un paisaje en sus geosistemas depende del conocimiento de los elementos que integran el medio natural, tanto biótico como abiótico, del conocimiento de las relaciones existentes entre éstos y en tercer lugar depende del análisis de la acción antrópica sobre ese determinado territorio, por ende, sobre los elementos que lo forman. 
Además de las propias características físicas del territorio y de las acciones relativamente incidentes del ser humano en el mismo, la delimitación de los geosistemas está estrechamente vinculada a la escala del área de estudio, pues los geosistemas se han de caracterizar por presentar elementos fisonómicos homogéneos, teniendo además un tamaño cartografiable (Ibarra Benlloch, 1993).

\section{LAS UNIDADES DE PAISAJE DEL ESPACIO SERRANO DE BÉJAR Y CANDELARIO COMO APLICACIÓN DE LA TIPOLOGÍA DEFINIDA}

Pertenecientes al gran eje estructural que supone el Sistema Central y situadas como límite administrativo entre las provincias de Salamanca, Cáceres y Ávila (fig. 4), las sierras de Béjar y Candelario se localizan en el contexto de transición entre las «montañas atlanticas»y las «montañas mediterráneas», pues adquieren tendencias bioclimáticas de los dos

LOCALIZACIÓN DE LOS MUNICIPIOS QUE CONSTITUYEN LAS SIERRAS DE BÉJAR Y CANDELARIO

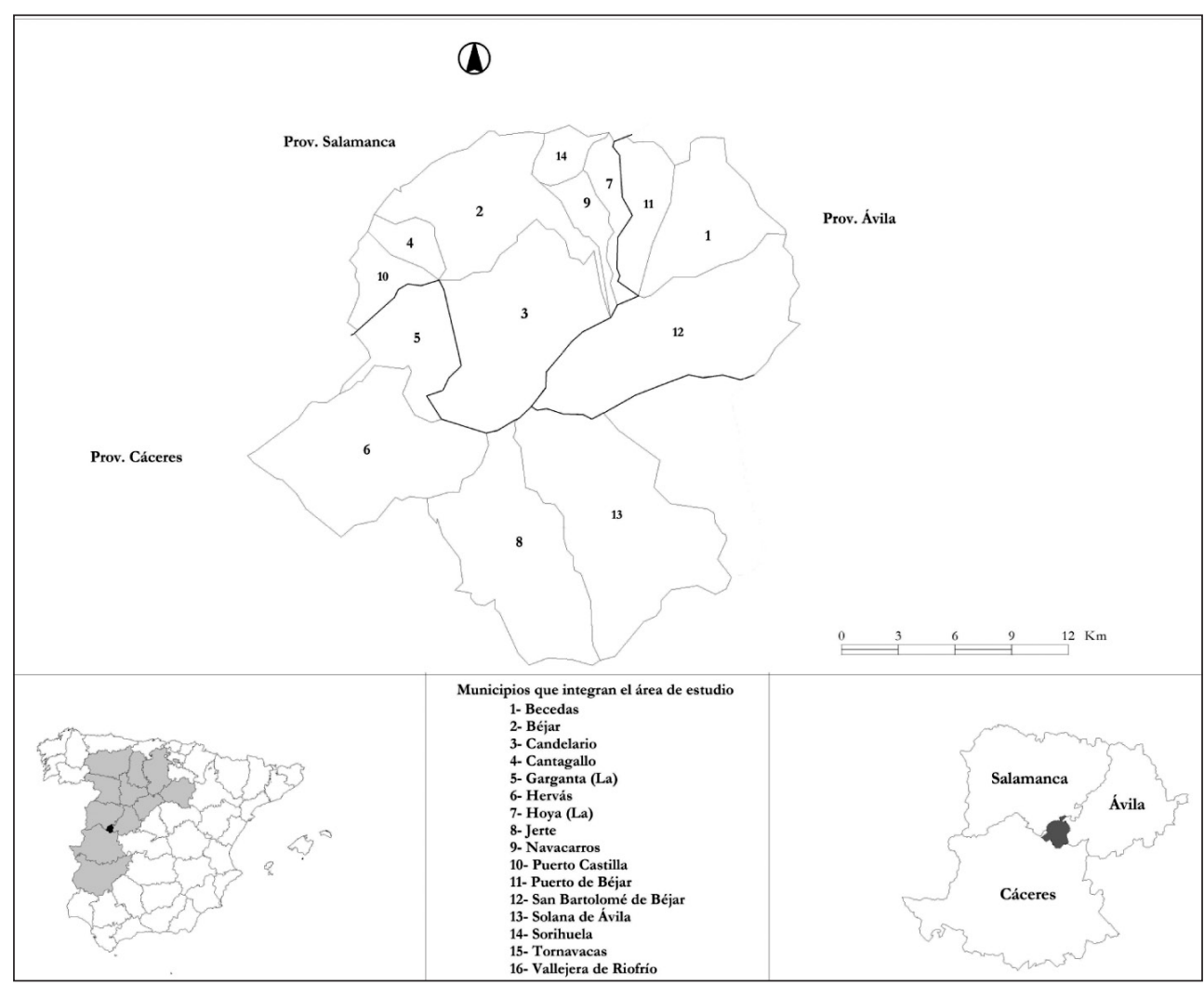

Fuente: elaborado a partir de la cartografía base de la Infraestructura de Datos Espaciales de España (IDEE). 


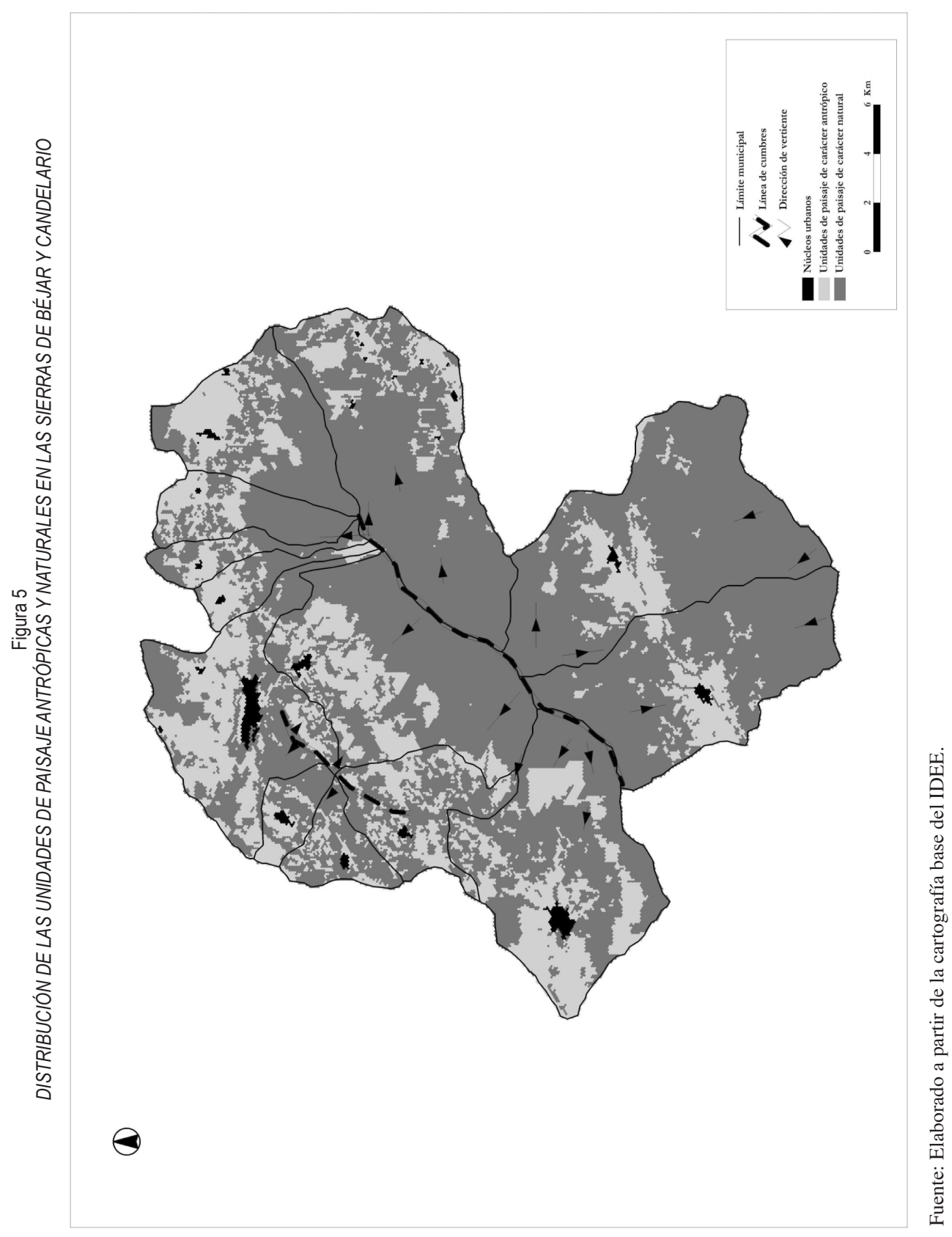


principales biomas ${ }^{6}$ que conciernen a la Península Ibérica: cantidad elevada de precipitaciones (clima atlántico) durante todo el año excepto en época estival, donde está presente el característico periodo de sequía propio de los climas mediterraneizados. A las características de las dos tendencias climáticas que afectan a las sierras de Béjar y Candelario hay que añadir las características climáticas locales de un espacio de montaña. Junto a las influencias meteorológicas, a los materiales ${ }^{7}$ que componen estas sierras y a los procesos geomorfológi$\cos ^{8}$ dinámicos y litoestructurales que han incidido en las mismas y que han sido los principales escultores paisajísticos de este macizo, hay que añadir la actividad antrópica, presente desde tiempos pretéritos, que se ha convertido en una muestra significativa de las actividades tradicionales ganaderas, principalmente, reflejada en los paisajes serranos.

La ubicación marginal con respecto a las capitales de provincia de las que ejerce como límite administrativo ha favorecido la preservación de los elementos naturales que sólo se han visto afectados por una somera actividad agrícola extinta y por la histórica actividad ganadera extensiva de carácter trashumante, a pesar de la potente industria textil que imperó en la ciudad de Béjar a mediados del siglo XX y que en la actualidad se encuentra en desuso. Por ello los paisajes naturales de las sierras de Béjar y Candelario han adquirido notable relevancia, salpicados por las unidades de paisaje propias de los usos ganaderos.

A grandes rasgos, y a modo de contexto introductorio que englobe todas las unidades de paisaje seleccionadas, es conveniente hacer una primera aproximación a las tres grandes unidades paisajísticas que agrupan la mayor parte de las unidades de paisaje tanto de carácter natural como de carácter antrópico (fig. 5), además de dar entidad y forma al paisaje de las sierras de Béjar y Candelario. Los paisajes de cumbres, los de transición o vertiente y los paisajes de valle, son las grandes unidades que, en conjunto, hacen posible la creación de un paisaje serrano singular de gran diversidad y valor.

\section{El paisaje de cumbres}

Se circunscribe a las partes superiores de la sierra, es la unidad paisajística de mayor altitud y posee la característica inherente de la nieve que durante gran parte del año otorga un carácter único a estos espacios. Esta unidad paisajística queda situada en la parte culminante de la sierra de Candelario, a partir de los 2.200 mts. de altitud ${ }^{9}$, presentando una característica propia de los relieves, como éste, de estructura germánica, que es la planicie culminante

6 La localización (en el tercio occidental del Sistema Central), la envergadura (superficie culminante relativamente isoaltitudinal en la Cuerda del Calvitero donde se alcanzan hasta los 2.428 metros de altitud) y la orientación (NNE-SSW) actúan de efecto pantalla transversal a los frentes procedentes del Atlántico, motivando así mayor índice de precipitaciones orográficas durante todo el año excepto en los meses de verano, cuando el anticiclón de las Azores desvía los frentes hacia el norte.

7 Las sierras de Béjar y Candelario se encuentran formadas por materiales antiguos, paleozoicos, principalmente granitos.

8 Los procesos geomorfológicos más representativos, además de los propios de creación del Sistema Central, tales como la tectónica de fractura y la creación de una estructura «germánica», y que han esculpido las sierras de Béjar y Candelario, son los resultantes de las acciones glaciares cuaternarias y de las acciones periglaciares actuales.

9 Isolínea, ésta, a partir de la cual la vertiente se suaviza pasando de una pendiente media de $15^{\circ}(26 \%)$ a una pendiente de apenas $3^{\circ}(5 \%)$. Esta ruptura en la pendiente nos sirve como punto significativo a partir del cual podemos diferenciar la zona de cumbres de la zona de vertiente o de transición. 
(penillanura de cumbres) y la isoaltitud conocida con el nombre de Cuerda del Calvitero; atendiendo a este topónimo que da nombre a estos niveles superiores, podemos tener una primera percepción del paisaje presente en este lugar. El topónimo Cuerda hace referencia a la línea de cumbres que presenta una morfología suave, de tendencia llana, por otra parte el topónimo Calvitero nos detalla un lugar sin vegetación, como su propio nombre indica un lugar «calvo». Se caracteriza por presentar una superficie culminante prácticamente plana, de roca desnuda con colores oscuros propios del granito y una acumulación de materiales rotos por la acción del hielo formando berrocales o canchales. Las subunidades de paisaje que se pueden encontrar en la unidad de paisaje de cumbres se ciñen a las propias de los elementos geológicos y geomorfológicos (fig. 1) salpicadas, en determinados lugares donde las condiciones son más propicias, por de las de pastizal ${ }^{10}$. Esta unidad de paisaje se ve complementada por los antiguos elementos glaciares y la actual actividad periglaciar (canchales, roca desnuda y escarpes).

\section{Paisaje de vertiente o transición}

Se extiende por las laderas de la sierra; su principal característica es la fuerte pendiente, pues en apenas 5 kilómetros se desciende desde los 2.428 metros de la Ceja (pico de mayor altitud de la sierra de Candelario) a los 1.100 metros en el valle del río Cuerpo de Hombre, aproximadamente una pendiente del $26 \%$ ó $15^{\circ}$ de desnivel. Es definida como zona de transición por ser la parte existente entre las cumbres y los valles; transición, pues, entre niveles o franjas altitudinales. En esta zona se pueden encontrar la gran diversidad de unidades de paisaje (fig. 1) definidas anteriormente en el apartado II.

Debido a las características estructurales de las sierras de Béjar y Candelario, es este espacio de vertiente el que ocupa mayor superficie dentro del entramado montañoso y también el más complicado a la hora de discernir entre unidades de paisaje, pues los límites entre unas unidades y otras son confusos produciéndose superposiciones, solamente apareciendo con bordes nítidos aquellas unidades de paisaje procedentes de las actividades antrópicas, tales como los espacios dedicados a la ganadería (que no se encuentren en estado de abandono) o los destinados a la repoblación forestal. Muy significativas son aquellas que han caído en el abandono, como es el caso del núcleo abandonado de Casas de la Sierra (localizado en el municipio de Solana de Ávila, en la vertiente oriental de la sierra de Candelario) o los espacios agrarios abandonados, pues éstos han sido recolonizados por especies vegetales autóctonas actuando, así, de ejemplo de la capacidad regeneradora de las mismas y sirviendo como modelo de la posible evolución paisajística de determinados espacios serranos.

La distribución de las unidades de paisaje dentro de esta gran unidad que supone la vertiente serrana, presenta una característica de zonalidad muy marcada (fig. 6), regida principalmente por el factor altitud y rota en determinadas áreas gracias al encasillamiento de

10 Se debe destacar que en las sierras de Béjar y Candelario la presencia de pastizales naturales es mínima debido a los condicionantes orográficos y de altitud, pues en los lugares de mayor altitud (Cuerda del Calvitero) la presencia de roca desnuda limita esta unidad. Los pastizales que se identifican en este espacio serrano han sido fomentados por la actividad ganadera, apareciendo, así, en lugares pertenecientes al dominio del matorral de Cytisus balansae (piorno serrano) como dan prueba de ello los espacios de pastizal abandonados que han sido colonizados por esta especie de matorral. 


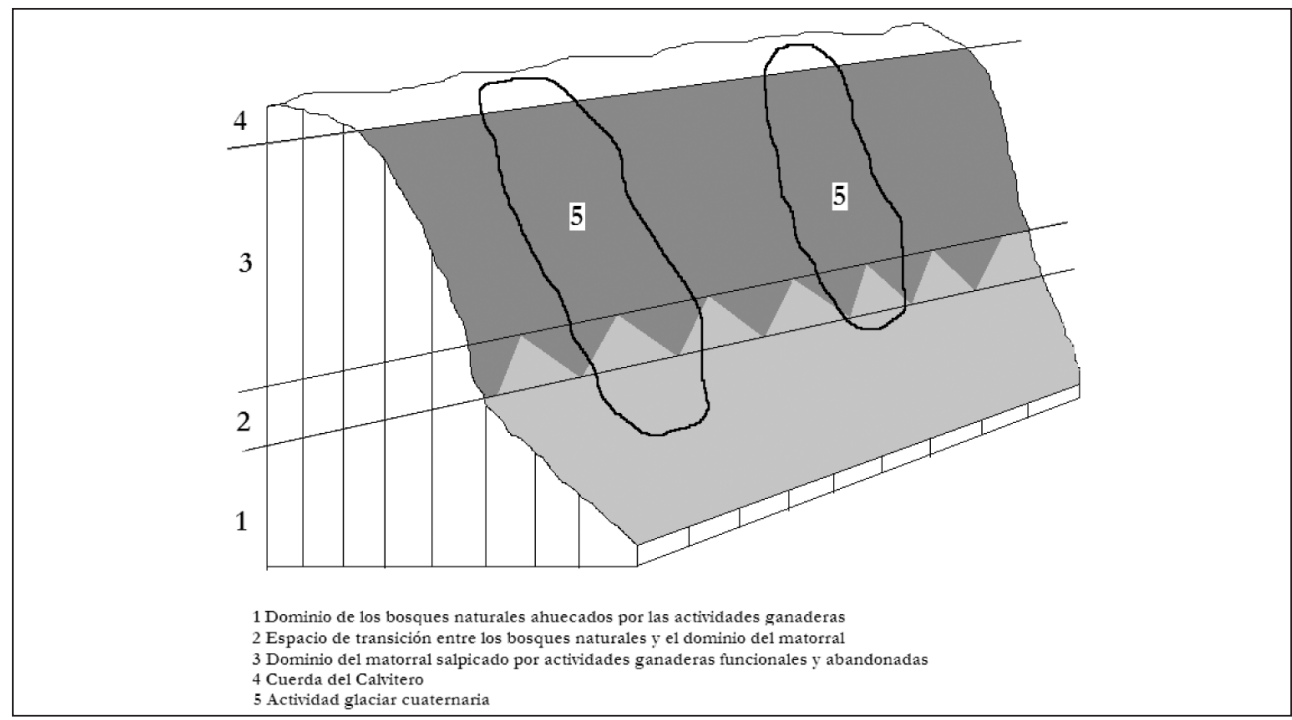

Fuente: Elaboración propia.

los espacios agrarios en aquellos lugares donde los condicionantes orográficos no actúan de forma tan limitante como en el resto del territorio. La distribución de las unidades de paisaje dentro de este espacio de vertiente se ciñe a la siguiente dinámica zonal (desde los espacios de menor altitud a los de mayor): en primer lugar se sitúan los bordes de mayor altitud de los restos de bosques naturales mixtos de Quercus pyrenaica (roble) y de Castanea sativa (castaño) ahuecados para usos ganaderos, apareciendo así las dos primeras unidades (bosque y usos ganaderos); después de un espacio de transición donde el bosque se va entrelazando con el matorral, aparece el dominio del matorral del género Cytisus, también restringido por las actividades ganaderas, actividades estas que se encuentran en estado de abandono (aparecen así dos nuevas unidades de paisaje, las de matorral y las de los espacios ganaderos abandonados, donde destaca la colonización de antiguas especies vegetales encaminadas hacia el estado climácico).Ya dentro de esta gran unidad que es, la de vertiente, también aparecen numerosas subunidades vinculadas a factores geológicos y geomorfológicos, tales como canchales asociados a acciones periglaciares, antiguas morrenas que debido al tamaño de los bloques graníticos no han sido colonizadas por la vegetación, exiguos valles glaciares donde la roca madre no favorece cualquier uso, etc. Todas ellas, de carácter estructural, no responden, de forma tan marcada, al patrón zonalidad.

\section{Paisaje de llanura y de valle}

Debido a las características estructurales de las sierras de Béjar y Candelario la presencia de este tipo de paisaje (de llanura o valle) no adquiere extensiones tan relevantes y tan defi- 
nidas como sucedía con los paisajes de cumbre o de vertiente (apartados 1 y 2, respectivamente, del presente epígrafe III). El paisaje de valle en este conjunto serrano se circunscribe al curso medio, con dirección SW-NE, del río Cuerpo de Hombre cuyo cauce ha modificado algunos de los espacios ocupados actualmente por los asentamientos poblacionales, favoreciendo así su aprovechamiento.

Se distribuyen por la zona de enlace de la vertiente («paisajes de transición») con la llanura o con el fondo de valle; es la zona donde se encuentran los núcleos urbanos, los paisajes de ribera (propiamente dichos, formados por el cauce y el curso de agua y por la vegetación propia de los espacios de ribera), etc. La característica principal puede ser la práctica ausencia de pendiente y la presencia de la mayor parte de los núcleos urbanos; así en esta zona encontramos la mayoría de las unidades paisajísticas de origen antrópico. Es el espacio serrano donde la presión humana ha actuado de forma más agresiva, deformando gran parte de las muestras naturales que por ella se extendían. Se trata de un paisaje de notable diversidad que alcanza, en términos absolutos de unidades de paisaje, valores significativos de riqueza paisajística ${ }^{11}$, pues es en estos lugares de valle o de enlace basal donde surgen el mayor número de unidades de paisaje. Esta mayor concentración de unidades de paisaje se encuentra directamente influida por la presencia antrópica, siendo la gran mayoría de las mismas consecuencia de los usos y aprovechamientos humanos.

\section{Definición, caracterización y delimitación de los geosistemas de las sierras de Béjar y Can- delario}

Dentro de la subdivisión paisajística zonal realizada en el contexto de las sierras de Béjar y Candelario (Paisaje de cumbres, Paisaje de vertiente o transición y Paisaje de valle y de piedemonte) y con ayuda de las unidades de paisaje identificadas, cuya combinación nos permite, junto con el conocimiento de los factores físicos y naturales de este espacio, identificar una serie de geosistemas con el objeto de aplicar éstas en el contexto del Análisis Sistémico del Paisaje, estando así en disposición de definir y caracterizar, de forma muy somera, los principales geosistemas que se localizan en este espacio serrano. Se trata de una breve definición, sin entrar en profundidad a detallar los elementos que los componen o la dinámica seguida por los mismos, pues para ello se necesitaría profundizar de forma muy precisa en los geosistemas potenciales, posteriormente la acción antrópica sobre los mismos, para concluir con el estadio evolutivo en el que se encuentran.

\subsection{Geosistema de las altas cumbres modelado por el glaciarismo}

Este geosistema se encuentra localizado en la zona de cumbres, siempre situado a niveles altitudinales superiores a los 2.200 metros. Está formado por las unidades correspondientes a los circos glaciares cuaternarios y a la actividad periglaciar. Presenta unas características orográficas marcadas por la ruptura de pendiente y por la presencia de una llanura de colmatación formada por las acciones de obturación glaciar, siendo un elemento significativo

11 Riqueza paisajística valorada en función del número de unidades de paisaje, tanto unidades antrópicas como naturales. 
de éste la presencia de una pequeña laguna. La actividad vegetal no representa un elemento condicionante de este geosistema, pues los condicionantes físicos, especialmente los geológicos (presencia de roca madre y ausencia de suelo apto para vida vegetal), y la presencia de los movimientos propios del periglaciarismo no favorecen el asentamiento de gran parte de las especies vegetales. El geosistema de las altas cumbres modelado por el glaciarismo se asienta sobre un sustrato geológico compuesto por materiales antiguos (paleozoicos) donde el granito en sus diferentes variedades es el máximo exponente. Como se menciona anteriormente la explotación biológica se lleva a cabo por algunas especies vegetales rupícolas que a la escala de trabajo no ejercen de condicionante en este geosistema. La actividad antrópica tiene su reflejo en forma de las unidades de pastizal (pradería, pues es incentivada por la acción humana) ocupando las antiguas lagunas colmatadas. En los espacios donde la actividad humana ha desaparecido son las unidades de matorral las que han ocupado ese espacio.

\subsection{Geosistema de la planicie culminante}

$\mathrm{Al}$ igual que el geosistema anterior, éste se encuentra localizado en niveles altitudinales superiores a los 2.200 metros y está formado por una sola unidad de paisaje que se corresponde con la de roca desnuda. Se trata de la planicie culminante de la Cuerda del Calvitero. La principal característica es la ausencia de pendiente. El sustrato base está compuesto por materiales graníticos esculpidos por las acciones mecánicas periglaciares formando pequeñas pedreras. La actividad biológica esta limitada a las especies vegetales rupícolas, cuya escasa presencia no llega a crear una unidad o geofacies significativa dentro de este geosistema.

\subsection{Geosistema de las vertientes modificadas por el glaciarismo}

Este geosistema se localiza entre los 2.200 y los 1.800 metros de altitud y está limitado por la presencia de los exiguos valles glaciares de las sierras de Béjar y Candelario. Dentro de éste se pueden diferenciar dos geosistemas dependiendo de la vertiente de localización, pues los valles glaciares de la vertiente este u oriental adquieren mayor potencia que los de la vertiente oeste, aunque los elementos generales de caracterización no varían entre una y otra vertiente. En este caso el factor pendiente (entre el $15 \%\left(9^{\circ}\right)$ y el $17 \%\left(10^{\circ}\right)$ ) obtiene notable importancia como limitante de algunos usos antrópicos (agricultura). Son varias las unidades que forman este geosistema, articuladas todas ellas por un valle de herencia glaciar. El sustrato sobre el que se asienta este geosistema es el correspondiente a rocas graníticas, aunque en él se identifican suelos con mayor densidad de materia orgánica dando la posibilidad de la presencia de actividad biológica de notable relevancia como es la formada por la unidad del estrato de matorral de Cytisus balansae (piorno serrano) como el más representativo. Aquí aparece una nueva unidad de carácter antrópico que se corresponde con los usos ganaderos (pradería extensiva en altura) cuya percepción incorpora nuevos elementos ortogonales, al geosistema, propios del sistema de cerrado de las parcelas ganaderas que consiste en un muro de roca autóctona. Es de destacar la presencia de la unidad correspondiente con los canchales creados gracias a la sedimentación glaciar en forma de morrenas, caracterizados por bloques angulosos de gran tamaño (superiores a los dos metros). 


\subsection{Geosistema de vertiente ocupado por Cytisus balansae y por bosques mixtos de Quercus pyrenaica y de Castanea sativa}

La localización de éste se produce entre los 2.200 y los $1.500 \mathrm{~m}$ de altitud, en aquellos lugares de la vertiente donde la huella glaciar no está presente. Al igual que en el caso anterior, en éste, la pendiente oscila entre el 15 y el $17 \%$ (entre 9 y $10^{\circ}$ respectivamente) con los mismos condicionantes limitantes. Este geosistema se repite en la ladera serrana alternando con el anterior. El sustrato geológico esta formado por los diversos tipos de granitoides presentes en el subsuelo, apareciendo, ahora sí, lugares donde la potencia de suelo apto para la vegetación adquiere niveles relevantes. En cuanto a la actividad biológica se divide según niveles altitudinales, llegando desde los 1.500 metros hasta los 1.800 metros de altitud aproximadamente la unidad de los bosques mixtos de Quercus pyrenaica y de Castanea sativa. Por lo que al estrato de matorral de Cytisus balansae se refiere, ocupa aquellos lugares altitudinales superiores a los 1.800 metros intercalado con la presencia de la unidad ganadera de los espacios de pasto.

\subsection{Geosistema del valle del río Cuerpo de Hombre}

El geosistema correspondiente al valle del río Cuerpo de Hombre presenta unas características de localización asociadas a su propio encajamiento aprovechando el valle resultante entre la sierra de Candelario y la pequeña sierra de Béjar. Se localiza entre los 1.400 y los $1.100 \mathrm{~m}$ de altitud, aproximadamente hasta su entrada en la ciudad de Béjar. La principal unidad de paisaje que se puede entresacar de este geosistema es la correspondiente a la unidad de ribera, formada por la vegetación propia de estos espacios y por el curso de un río. El sustrato sobre el que se desarrolla sigue la tónica de los geosistemas anteriores, es decir sobre suelos graníticos con notable grado de desarrollo del perfil edáfico correspondiente al de materia orgánica.

La actividad biológica de éste está en relación con la vegetación de ribera, siendo lo más relevante la presencia de Populus alba (chopo) y Fraxinus angustifolia (fresno).

En cuanto a la actividad antrópica dentro de este geosistema aparecen dos nuevas unidades vinculadas a los usos ganaderos; por un lado, la ya mencionada unidad de pradería y por otro, la unidad referente a los usos intensivos de aprovechamiento ganadero, principalmente infraestructuras de estabulación y manejo del ganado. Además de las dos unidades anteriores, la unidad de paisaje correspondiente a los usos urbanos diseminados adquiere notable protagonismo, salpicando los bosquetes mixtos y los espacios ganaderos.

\subsection{Geosistema de piedemonte y de aprovechamientos urbanos}

Se trata del geosistema donde la acción antrópica ha adquirido mayor reflejo, pues tanto los condicionantes orográficos como los climáticos, no influyen tan directamente sobre las actividades humanas, como ocurría en los geosistemas anteriores. Éste se localiza entre los $1.500 \mathrm{y}$ los $1.100 \mathrm{~m}$ de altitud, donde los niveles de pendiente descienden hasta el $7 \%$ $\left(4^{\circ}\right)$. El sustrato identificado en este geosistema sigue las características de los geosistemas anteriores, es decir materiales graníticos. El perfil edáfico correspondiente al de la materia 
orgánica alcanza niveles relativamente óptimos, siempre teniendo en cuenta que se trata de un espacio de montaña donde el factor gravedad, acompañado de las numerosas precipitaciones, desarrollan el efecto lavado de la capa orgánica. Las unidades de paisaje antrópicas adquieren mayor relevancia en este geosistema, encontrando en él todos los tipos de unidades que se definieron, anteriormente, en el apartado II.2. Además de las unidades ganaderas de aprovechamientos intensivos, las unidades relativas a los núcleos urbanos se localizan aprovechando la benignidad de las pendientes limitadas y el cobijo climático.

Dentro de este geosistema se localiza una unidad especial, la unidad de paisaje de los polígonos industriales, vinculada a la de la ciudad de Béjar. Supone un elemento perceptivo que introduce nuevos aspectos geométricos en el paisaje.

En cuanto a la actividad biológica queda circunscrita a los restos de bosque mixto de Quercus pyrenaica y de Castanea sativa que han sido ahuecados para el aprovechamiento agrario.

\section{CONCLUSIONES}

En el marco conceptual y normativo del CEP se destaca notablemente el dinamismo del paisaje como cualidad de éste. A la hora de analizar e investigar la dinámica del paisaje surge el problema, de difícil solución, asociado con la escala temporal, pues al acometer un estudio paisajístico es necesario sentar las bases temporales sobre las que se va a detallar el mismo. Siendo ésta una de las preocupaciones, junto con la preservación del paisaje, del CEP, el marco metodológico de estudio del paisaje está siendo orientado hacia la temática del mismo asociado con los aspectos evolutivos. En este artículo se ha presentado una aproximación metodológica encaminada a localizar y discernir los diferentes elementos que forman el paisaje de montaña, utilizando para ello como ejemplo de aplicación las sierras de Béjar y Candelario (SW de la provincia de Salamanca) y su empleo dentro de un sistema consolidado de análisis del paisaje como es el Análisis Sistémico del Paisaje. Una vez caracterizadas las unidades del paisaje y con los conocimientos previos del medio físico se han podido interrelacionar con el objeto de identificar los geosistemas más relevantes de este conjunto serrano. La identificación, previa, de las unidades del paisaje ha facilitado la interrelación de éstas pudiendo así definir una serie de geosistemas. Uno de los objetivos perseguidos en esta investigación era poder analizar el paisaje siguiendo las pautas teóricas que se desprenden del CEP sin entrar en aquellos criterios de dinamismo, pues para llegar a ello es necesario superar un primer paso de conocimiento de los elementos condicionantes del paisaje, aspectos en los que se ha centrado este texto.

La definición de las unidades de paisaje elaboradas y posteriormente la aplicación de los geosistemas al espacio natural protegido de las sierras de Béjar y Candelario nos ha permitido dar una primera visión, muy somera, de los elementos que forman este paisaje serrano y las interrelaciones que surgen de ellos, destacando de entre los resultados obtenidos la amenaza que puede suponer la dinámica imperante de abandono de las actividades tradicionales que han fomentado la diversidad y riqueza de este paisaje, además de la presencia de factores negativos tales como la urbanización masiva de carácter diseminado que se ha implantado desde mediados de los años ochenta del siglo pasado. Es de destacar, en la actualidad, la incontestable calidad natural de este paisaje serrano, donde la presencia humana, desde tiem- 
pos pretéritos, ha sabido conjugar los usos y aprovechamientos con la sostenibilidad del medio.

\section{BIBLIOGRAFÍA}

BERTRAND, G. (1968): «Paysage et géographie physique globale. Esquisse methodologique». Reveu géografhique des Pyrénées et du Sud-Ouest, vol. 39, pp. 249-272

BERTRAND, G. (1978): «Le paysage entre la nature et la société». Reveu Géografhique des Pyrénées et du Sud-Ouest, vol. 49, pp. 239-258.

BERTRAND, G. y BERTRAND, C. (2006): Geografía del medio ambiente. El sistema GTP: geosistema, territorio y paisaje. Granada. Servicio de publicaciones de la Universidad de Granada.

BOLÓS I CAPDEVILA, M. de (1992): Manual de ciencia del paisaje. Barcelona. Ed. Masson.

COMUNITAT VALENCIANA (2006): «Decreto 120/2006, Reglamento de paisaje de la Comunidad Valenciana». Diari Oficial de la Comunitat Valenciana, $\mathrm{n}^{\circ} 5325$ de 16 de agosto de 2006.

CONSEJO DE EUROPA (2000): Convenio Europeo del Paisaje. Florencia. Consejo de Europa.

DE LUCIO, J. et al., (1990): Cartografía de paisaje de la Comunidad autónoma del País Vasco. Vitoria. Departamento interuniversitario de ecología de Madrid, Departamento de proyectos y de planificación rural de la Universidad Politécnica de Madrid y Gobierno Vasco.

DOLLFUS, O. (1978): El análisis geográfico. Barcelona. Editorial Oikos-Tau.

IBARRA BENLLOCH, P. (1993) «Una propuesta metodológica para el estudio del paisaje integrado». Geographicalia, no 30, pp. 229-242.

GÓMEZ ZOTANO, J. (2006): Naturaleza y paisaje en la Costa del Sol occidental. Málaga. Servicio de publicaciones de la Diputación de Málaga.

JIMÉNEZ OLIVENCIA, Y. y PORCEL RODRÍGUEZ, L. (2008): «Metodología para el estudio evolutivo del paisaje: aplicación al espacio protegido de Sierra Nevada».Cuadernos Geográficos, n 43 , pp. 151-179.

LÓPEZ BARAJAS, R y CERVANTES BORJA, J. (2002): «Unidades del paisaje para el desarrollo sustentable y manejo de los recursos naturales». Revista de Información y Análisis, no 20, pp. 43-49.

MARTÍNEZ DE PISÓN, E. (2000a): «Imagen de la naturaleza de las montañas», en Martínez de Pisón, E. (Dir.): Estudios sobre el paisaje Murcia, Ediciones de la Universidad Autónoma de Madrid, pp. 15-54.

MARTÍNEZ DE PISÓN, E. (2000b): «La protección del paisaje. Una reflexión» en Martínez de Pisón, E. (Dir.): Estudios sobre el paisaje. Murcia, Ediciones de la Universidad Autónoma de Madrid, pp. 215-236.

MARTÍNEZ DE PISÓN, E. (2009): Miradas sobre el paisaje. Madrid. Editorial Biblioteca Nueva.

MATA OLMO, R. (2004): «Agricultura, paisaje y gestión del territorio». Polígonos, $\mathrm{n}^{\mathrm{o}} 14$, pp. $97-138$. 
MEAZA, G. y ORMAETXEA, O. (1992): «Propuesta metodológica de valoración fitogeográfica de unidades de paisaje vegetales». Cuadernos de Sección. Historia, n 20, pp. 369-389.

MOLINERO HERNANDO, F., ALARIO TRIGUEROS, M. y BARAJA RODRÍGUEZ, E. (2009): «Unidades escalares de los paisajes agrarios en España». En Pillet Capdepón, F., Cañizares Ruiz, M.C. y Ruiz Pulpón (Coords.): Geografía, territorio y paisaje: el estado de la cuestión: actas del XXI Congreso de Geógrafos Españoles. Ciudad Real, Universidad de Castilla-La Mancha y Asociación de Geógrafos Españoles, pp. 1.211-1.229.

NOGUÉ, J. (2007): «El observatorio del paisaje y los catálogos del paisaje de Cataluña». En Martínez de Pisón, E. y Ortega Cantero, N. (Eds.): La conservación del paisaje en los Parques Nacionales. Madrid. Fundación Duques de Soria.

ORTEGA CANTERO, N. (2000): «Las raíces culturales de la conservación de los paisajes» en Martínez de Pisón, E. (Dir.): Estudios sobre el paisaje. Murcia, Ediciones de la Universidad Autónoma de Madrid, pp. 237-258.

RIBAS VILÁS, J. (1992): «Análisis y diagnosis», en De Bolos, M. (Dir.): Manual de ciencia del paisaje. Teoria, métodos y aplicaciones. Barcelona. Ed. Masson, pp. 135-153.

SABATE BEL, J. y VERA GALVÁN, J.R. (2008): «Aspectos varios de la implementación de la Convención Europea del Paisaje en el Plan Territorial Especial Ordenación del Paisaje de Tenerife». Cuadernos Geográficos, n 43, 51-67.

SANZ HERRAÍZ, C. (2000): «El paisaje como recurso», en Martínez de Pisón, E. (Dir.):Estudios sobre el paisaje. Murcia, Ediciones de la Universidad Autónoma de Madrid, pp. 281-292.

SILVA PÉREZ, R. (2009): «Agricultura, paisaje y patrimonio territorial. Los paisajes de la agricultura vistos como patrimonio». Boletín de la Asociación de Geógrafos Españoles, $\mathrm{n}^{\circ} 49$, pp. 334 .

ZOIDO NARANJO, F. (2000): «Líneas en la protección del paisaje» en Martínez de Pisón, E., (Dir.): Estudios sobre el paisaje. Murcia, Ediciones de la Universidad Autónoma de Madrid, pp. 293-312. 
